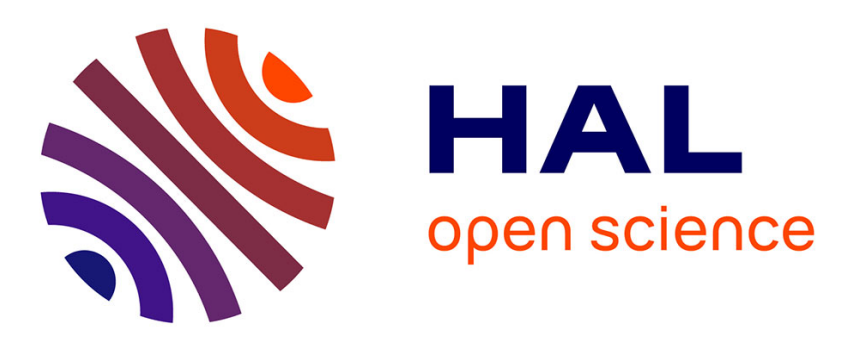

\title{
Ultrafast Delamination of Graphite into High-Quality Graphene Using Alternating Currents
}

Sheng Yang, Antonio Gaetano Ricciardulli, Shaohua Liu, Renhao Dong, Martin R. Lohe, Alfons Becker, Marco A. Squillaci, Paolo Samorì, Klaus Müllen, Xinliang Feng

\section{To cite this version:}

Sheng Yang, Antonio Gaetano Ricciardulli, Shaohua Liu, Renhao Dong, Martin R. Lohe, et al.. Ultrafast Delamination of Graphite into High-Quality Graphene Using Alternating Currents. Angewandte Chemie International Edition, 2017, 56 (23), pp.6669-6675. 10.1002/anie.201702076 . hal-02511621

\section{HAL Id: hal-02511621 \\ https://hal.science/hal-02511621}

Submitted on 18 Mar 2020

HAL is a multi-disciplinary open access archive for the deposit and dissemination of scientific research documents, whether they are published or not. The documents may come from teaching and research institutions in France or abroad, or from public or private research centers.
L'archive ouverte pluridisciplinaire HAL, est destinée au dépôt et à la diffusion de documents scientifiques de niveau recherche, publiés ou non, émanant des établissements d'enseignement et de recherche français ou étrangers, des laboratoires publics ou privés. 


\title{
Ultrafast Delamination of Graphite into High-Quality Graphene Using Alternating Currents
}

\author{
Sheng Yang ${ }^{[a, b]}$, Antonio Gaetano Ricciardulli ${ }^{[b]}$, Shaohua Liu ${ }^{[a]}$, Renhao Dong ${ }^{[a]}$, Martin R. Lohe ${ }^{[a]}$, \\ Alfons Becker ${ }^{[b]}$, Marco A. Squillaci ${ }^{[c]}$, Paolo Samori ${ }^{[c]}$, Klaus Müllen ${ }^{[b] *}$, Xinliang Feng ${ }^{[a] *}$
}

\begin{abstract}
To bridge the gap between laboratory-scale study and commercial applications, mass production of high quality graphene is essential. Here we present a scalable exfoliation strategy towards the production of graphene sheets with excellent yield $(\sim 75 \%, 1-3$ layers), low defect density (a C/O ratio of 21.2), great solutionprocessability and outstanding electronic property (a hole mobility of $\left.430 \mathrm{~cm}^{2} \cdot \mathrm{V}^{-1} \cdot \mathrm{s}^{-1}\right)$. By applying alternating currents, dual exfoliation at both graphite electrodes enables a high production rate exceeding $20 \mathrm{~g} \mathrm{~h}^{-1}$ in laboratory tests. As a cathode material for lithium storage, graphene-wrapped $\mathrm{LiFePO}_{4}$ particles deliver a high capacity of 167 $\mathrm{mAh} \mathrm{g}^{-1}$ at $1 \mathrm{C}$ rate after 500 cycles.
\end{abstract}

Global progress in graphene research is expected to unlock a new era in the next generation of electronics. However, the development of scalable and cost-effective production of high quality graphene is required in order to offer a commercial prospect to this "wonder material". Thanks to the cheap and abundant graphite resource, graphene can be produced at low cost. The exfoliation of graphite, consequently, represents a reliable strategy to extend the outstanding features of individual graphene flakes to a macroscopic scale.

Graphene layers have been successfully detached from the parent graphite crystal by mechanical force in solid state $e^{[1]}$ or in liquid phase. ${ }^{[2]}$ Especially, wet-chemical approaches have been extensively studied because of the ease of synthesis and potential solution processability. ${ }^{[3]}$ The chemical routes (e.g. Hummer's method) allow for the large-scale production of graphene oxide (GO) with high yield of nearly $100 \%$, based on the weight ratio between dispersed graphitic material to starting graphite flakes. ${ }^{[4]}$ However, even through the use of harsh reduction processes, the residual oxide groups along with diverse structural defects radically affect the electronic features of the reduced GO flakes..$^{[5]}$ Beyond that, liquidphase sonication of graphite in organic solvents (e.g. N-methyl-2pyrrolidone) provides graphene flakes with much fewer defects. ${ }^{[6]}$

[a] S. Yang, Dr. S. Liu, Dr. R. Dong, Dr. M. R. Lohe, Prof. X. Feng Center for Advancing Electronics Dresden (cfaed) and Department of Chemistry and Food Chemistry, Technische Universität Dresden, Mommsenstraße 4, 01062 Dresden, Germany

E-mail: xinliang.feng@tu-dresden.de

[b] S. Yang, A. G. Ricciardulli, A. Becker, Prof. K. Müllen Max-Planck-Institut für Polymerforschung, Ackermannweg 10, 55128, Mainz, Germany E-mail: muellen@mpip-mainz.mpg.de

[c] M. A. Squillaci, Prof. P. Samori

University of Strasbourg, CNRS, ISIS UMR 7006, 8 allée Gaspard Monge, F-67000 Strasbourg, France

Supporting information for this article is given via a link at the end of the document
Nevertheless, these methods require long-lasting agitation (e.g. 24 hours), giving low exfoliation yields (less than $1 \%$ ) and limited sheet sizes (below $1 \mu \mathrm{m}) \cdot{ }^{[7]}$ Although higher exfoliation yield $(\sim 3 \%)$ and production rate $\left(1.44 \mathrm{~g} \mathrm{~h}^{-1}\right)$ have been achieved by means of shear exfoliation process in liquids, ${ }^{[8]}$ such method remains premature for industrial applications.

Alternatively, when graphite is used as working electrode in an electrochemical cell, an electric current drives the migration of ions or charged molecules into graphite interlayer spacings and pushes graphene layers apart. ${ }^{[9]}$ Electrochemical exfoliation is particularly facile, low-cost, eco-friendly yet efficient. ${ }^{[10]}$ It occurs at either anode (in dilute aqueous solution of ionic liquids, ${ }^{[11]}$ mineral acids ${ }^{[12]}$ or inorganic salts ${ }^{[13]}$ ) or cathode (in organic solvents containing lithium salts $^{[14]}$ or quaternary ammonium salts ${ }^{[15]}$ ), but not both. Anodic exfoliation gives excellent production rate (exceeding $10 \mathrm{~g} \mathrm{~h}^{-1}$ ), thinlayer (e.g. monolayer and bi-/tri-layer) graphene flakes with high yield $(\sim 70 \%)$ and large lateral size (5 $\mu \mathrm{m}$ in average) $\cdot{ }^{[13 a]}$ However, the obtained graphene inevitably contains a certain amount of oxygen groups, resulting from the attack of oxygen-containing radicals $(\mathrm{HO} \cdot, \mathrm{O} \cdot)$ by water splitting. ${ }^{[12 \mathrm{a}]}$ On the other hand, cathodic exfoliation, which benefits from reduction potential, guarantees pristine graphene sheets but mainly with thick layers (> 5 layers) and relatively low production rate $\left(0.5-2 \mathrm{~g} \mathrm{~h}^{-1}\right),{ }^{[16]}$ due to insufficient ion intercalation. In spite of the remarkable progress in this field, a wellsuited exfoliation method in terms of ultrahigh efficiency, outstanding graphene quality and excellent scalability is still missing.

Herein, we demonstrate a novel scalable exfoliation protocol using alternating current $(\mathrm{AC})$ in aqueous solution of organic sulfate salts, producing high-quality graphene with outstanding yield ( $80 \%)$. For the first time, dual intercalation/exfoliation has been achieved at both electrodes simultaneously, enabling ultrahigh production rate (exceeding $20 \mathrm{~g} \mathrm{~h}^{-1}$ in laboratory trials). Over $75 \%$ of thin flakes are 1-3 layer thick and exhibit lateral sizes ranging from 1 to $5 \mu \mathrm{m}$. In addition, the switch of voltage polarity facilitates in-situ reduction during the exfoliation process, suppresses structural damage and/or residual contamination from anodic oxidation, thereby providing graphene sheets with low defect density $\left(\mathrm{l}_{\mathrm{d}} / \mathrm{l}_{\mathrm{g}}<0.2\right.$ in Raman spectra). Field-effect mobility measured on a single graphene flake is as high as $430 \mathrm{~cm}^{2} \cdot \mathrm{V}^{-1} \cdot \mathrm{s}^{-1}$. More importantly, exfoliated graphene with excellent solution dispersibility paves the way to fabricating hybrid composites and conductive films. As a proof-of-concept, we demonstrate that graphene-wrapped commercial $\mathrm{LiFePO}_{4}$ particles reveal remarkable cycling stability in lithium-ion battery, delivering a high capacity of $167 \mathrm{mAh} \mathrm{g}^{-1}$ at $1 \mathrm{C}$ rate after 500 cycles. 
The experimental strategy is illustrated in Figure 1a. The exfoliation process was conducted in an electrochemical system, consisting of two graphite foils as anode and cathode, tetra- $n$-butyl-ammonium bisulfate $\left(\mathrm{TBA} \cdot \mathrm{HSO}_{4}\right)$ aqueous solution $(0.1 \mathrm{M}, \mathrm{pH}=1.8)$ as conductive media, respectively. The electrolyte was calibrated with sodium hydroxide $(\mathrm{NaOH})$ solution to nearly neutral condition $(\mathrm{pH}=6.5) . \quad\left(\mathrm{HSO}_{4}^{-} \leftrightarrow \mathrm{SO}_{4}^{2-}+\mathrm{H}^{+} ; \mathrm{HSO}_{4}^{-}+\mathrm{OH}^{-} \rightarrow \mathrm{SO}_{4}^{2-}+\mathrm{H}_{2} \mathrm{O}\right)$. We used a homemade setup with the capability to output alternating current with tunable frequency (from $0.01 \mathrm{~Hz}$ to $20 \mathrm{~Hz}$ ) (Fig. 1b, Fig. S1). Graphite foils at both electrodes dissolved quickly once an alternating current $( \pm 10 \mathrm{~V}, 0.1 \mathrm{~Hz})$ was applied, accompanied with violent eruption of bubbles. Eventually, graphite foils immersed inside the electrolyte would be entirely exfoliated (Fig. 1c, 1d). The suspended exfoliated graphene (EG) flakes on top of the electrolyte were collected by vacuum filtration. Repeated washing with water/ethanol was performed to eliminate the residue salts. To show the potential for large-scale production, five groups of graphite foils (10 pieces) were used in a laboratory trial, producing 5.50 gram EG flakes within $15 \mathrm{~min}$, with a high yield up to $80 \%$ (Fig. 1e). The production rate was translated to about $20 \mathrm{~g} \cdot \mathrm{h}^{-1}$. It is worth noting that the scalable production of EG relies on the size of graphite foils and the volume of electrochemical cell. The throughput can thus be easily increased to a higher level by setup engineering. Afterwards, graphene sheets were directly dispersed in $\mathrm{N}, \mathrm{N}$-dimethylformamide (DMF) without surfactant stabilization, affording a homogeneous dispersion $\left(0.10 \mathrm{mg} \mathrm{mL}^{-1}\right)$, stable for at least 4 weeks without agglomeration (Fig. 1f).

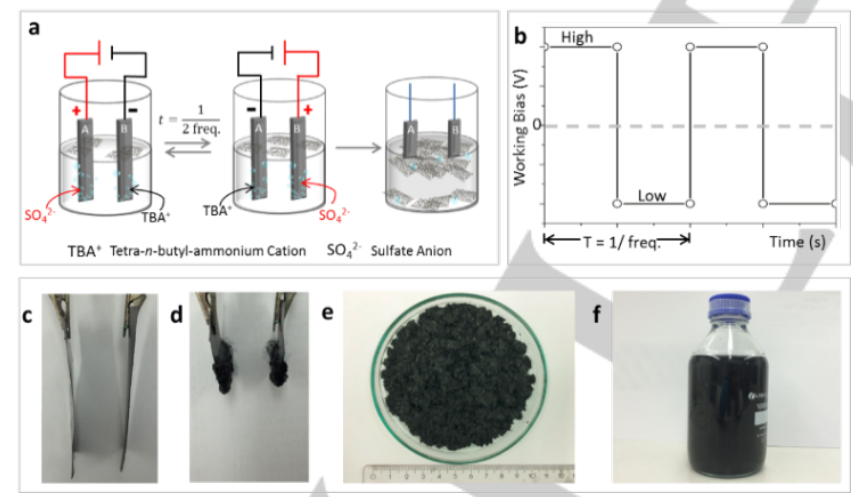

Figure 1. a) Scheme of graphite exfoliation via alternating current in aqueous solution of TBA. $\mathrm{HSO}_{4}$; b) The curves of working bias at anode, in which the polarity changes from positive to negative every $0.5 \mathrm{~T}$; c, d) Optical images of graphite foil before and after exfoliation; e) Mass production of EG in $15 \mathrm{~min}$; f) Stable EG dispersion in DMF (0.10 $\mathrm{mg} \mathrm{mL}^{-1}$ ).

Two types of organic bisulfates (i.e TBA. $\mathrm{HSO}_{4}$ and TMA. $\mathrm{HSO}_{4}$ (tetra-methyl-ammonium bisulfate)) were investigated at $\pm 10 \mathrm{~V}$ with different current frequencies spanning from $0.05 \mathrm{~Hz}$ to $0.25 \mathrm{~Hz}$. Although the cationic diameter of $\operatorname{TBA}^{+}(0.83 \mathrm{~nm})$ was larger than that of $\mathrm{TMA}^{+}(0.56 \mathrm{~nm}),{ }^{[15]}$ the former ion was found to be more efficient for the exfoliation. The possible explanation is that the flexibility of alkyl groups enables a flattened TBA ${ }^{+}$conformation $(0.47$ $\mathrm{nm}$, the vertical diameter), the size of which is comparable to the distance of graphitic interlayers $(0.33 \mathrm{~nm}){ }^{[17]} \mathrm{TBA}^{+}$permits the production of EG with lower oxygen content than that from $\mathrm{TMA}^{+}$. For example, as shown in Fig. S2, when $\mathrm{f}=0.25 \mathrm{~Hz}$ was applied, the resultant EG from $\mathrm{TBA}^{+}$exhibited 5.4 atom \% oxygen, based on $\mathrm{X}$ ray photoelectron spectroscopy (XPS), whilst EG from $\mathrm{TMA}^{+}$ delivered much higher oxygen content (10.1 atom \%) under the same condition. When $\mathrm{f}=0.1 \mathrm{~Hz}$ was applied, the oxygen level decreased to 7.1 atom $\%$ for $\mathrm{TMA}^{+}$, and 4.5 atom $\%$ for $\mathrm{TBA}^{+}$, respectively. Moreover, the working bias had great impact on the properties of the achieved EG. For example, when it changed from $\pm 6 \mathrm{~V}$ to $\pm 12 \mathrm{~V}$ at $\mathrm{f}=0.1 \mathrm{~Hz}$, the concentration of $\mathrm{EG}$ dispersion and the defect density of $E G$ (i.e. $I_{d} / l_{g}$ ratio by Raman spectroscopy) respectively decreased from 0.20 to $0.08 \mathrm{mg} \cdot \mathrm{mL}^{-1}$, and from 0.81 to 0.15 (Fig. S3). Therefore, a moderate potential of $\pm 10 \mathrm{~V}$ was applied for graphite exfoliation.

To explore the mechanism of the exfoliation process, we have compared alternating current $(\mathrm{AC})$ with conventional direct current (DC) in the solution of organic bisulfate salt (TBA. $\mathrm{HSO}_{4}$ ) (Fig. S4). When DC was applied, graphite delamination occurred at anode and cathode, however, the efficiency at the cathode was much inferior to that at the anode. By applying an AC, the efficiency at both electrodes was greatly increased, indicating that the working bias had great impact on ion diffusion as well as their intercalation behavior. Despite this, dual exfoliation was not observed in other aqueous electrolytes. For instance, in ammonium sulfate $\left(\left(\mathrm{NH}_{4}\right)_{2} \mathrm{SO}_{4}\right)$ solution, the exfoliation took place only at the graphite anode. The positively charged counterpart $\left(\mathrm{NH}_{4}{ }^{+}\right)$did not show any apparent effects at the cathode; thus the overall efficiency could be hardly improved, even upon switching the potential.

Based on the previous studies, ${ }^{[12-13]}$ the intercalation of guest ions is a significant step in the exfoliation process. By alternating current, graphite anode and cathode undergo two distinct intercalation routes (Scheme 1). We propose:

At the anode side, initially, high overpotential $(+10 \mathrm{~V})$ triggers countless oxygen-containing radicals $(\mathrm{HO} \text { and } \mathrm{O} \cdot)^{2}$ at the graphite/water interfaces: ${ }^{[18]}$

$$
\mathrm{H}_{2} \mathrm{O} \longrightarrow \mathrm{HO}^{\circ}+\mathrm{H}^{+}+\mathrm{e}^{-} \longrightarrow \mathrm{O} \bullet+2 \mathrm{H}^{+}+2 \mathrm{e}^{-}
$$

These radicals in turn attack the boundaries or intrinsic defects in graphite, opening the edges. This is a key step for the intercalation, however, inevitably introduces oxide groups. Afterwards, the migration of sulfate anions causes an increasing $d$-spacing distance (0.46 nm, the diameter of sulfate anion $\left.{ }^{[19]}\right)$. When the anodic potential switches from positive to negative, the intercalated sulfate anions will be reduced into gas bubbles: 


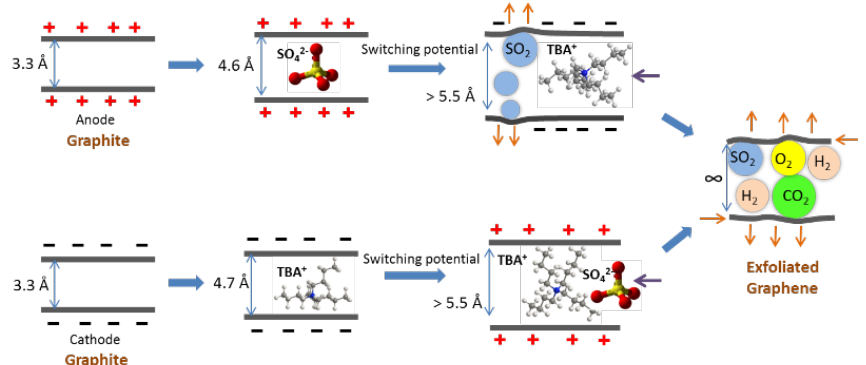

Scheme 1. Proposed mechanism for graphite exfoliation when applied with alternating current.

$$
\mathrm{SO}_{4}{ }^{2-}+2 \mathrm{e}^{-}+4 \mathrm{H}^{+} \longrightarrow \mathrm{SO}_{2}+2 \mathrm{H}_{2} \mathrm{O}
$$

Gas eruption inside graphite results in large forces, ${ }^{[12 a]}$ which further increase the distance between two neighbouring layers. Meanwhile, $\mathrm{TBA}^{+}$cations are supposed to intercalate inside.

$$
\mathrm{TBA}^{+}+\mathrm{e}^{-} \rightarrow \text { TBA (l) }
$$

Although they do not contribute to the formation of bubbles, the enhanced intercalation of TBA ${ }^{+}$indeed improves the exfoliation yield, owing to its relatively large size $(4.7 \AA-8.9 \AA$, varying with its conformation $^{[17]}$ ), which helps to overcome the interlayer Van der Waals forces. The force fades quickly once the interlayer distance of graphite exceeds $5.5 \AA .{ }^{[20]}$ More importantly, the negative potential is able to kick out previously attached oxygen-containing functionalities by electrochemical reduction, ${ }^{[21]}$ which is, to a great extent, favourable to improve the quality of exfoliated graphene flakes.

At the cathode side, at the beginning, the intercalation of $\mathrm{TBA}^{+}$ cations is not as effective as the anodic intercalation of sulfate anions because only the flattened conformation $(4.7 \AA)$ is able to accommodate inside graphitic layers. However, when the working bias shifts to positive values, due to the intercalation of sulfate ions, expanded graphite interlayer spacing is able to host tetrahedral conformation of $\mathrm{TBA}^{+}$cations, which facilitate a maximum gallery expansion of $8.9 \AA .^{[17]}$

Once both anode and cathode are expanded to a large extent, the complex electrochemical reactions at the liquid/solid interface generate massive bubbles $\left(\mathrm{O}_{2}, \mathrm{H}_{2}, \mathrm{SO}_{2}, \mathrm{CO}_{2}\right){ }^{\left[{ }^{[22 a]}\right.}$ The species of gases have been confirmed by infrared gas analysis (Fig. S5). The interplay between chemical reactions and mechanical deformation eventually peels off graphene layers from parent electrodes. ${ }^{[22 b]}$

$$
\begin{aligned}
& 2 \mathrm{H}_{2} \mathrm{O} \rightarrow \mathrm{O}_{2}+4 \mathrm{H}^{+}+4 \mathrm{e}^{-} \\
& 2 \mathrm{H}_{2} \mathrm{O}+2 \mathrm{e}^{-} \rightarrow \mathrm{H}_{2}+2 \mathrm{OH}^{-} \\
& \mathrm{C}_{x}+2 \mathrm{H}_{2} \mathrm{O} \rightarrow \mathrm{C}_{\mathrm{x}-1}+\mathrm{CO}_{2}+4 \mathrm{H}^{+}+4 \mathrm{e}^{-}
\end{aligned}
$$

The dissolution of graphite electrodes was confirmed by optical microscopy. In Fig. S6a, at a selected area of graphite foil, the exfoliation initiated at the boundaries, spreading to the central parts. The exfoliation speed was very high; apparent cracks at the edges were observed in less than 10 seconds. Within 40 seconds, the majority of graphite foils collapsed and broke down into small fragments. The cross-sectional views from SEM images (Fig. S6bS6c) clearly identified the morphological changes at the graphite anode and cathode separately. In the first 5 seconds, the cathode was less expanded than the anode because the intercalation of $\mathrm{TBA}^{+}$cations was more difficult than that of sulfate anions. From 5 to $10 \mathrm{~s}$, the polarity of electrodes was switched, the subsequent migration of $\mathrm{TBA}^{+}$cations and sulfate anions were boosted at the previously activated graphite electrodes, leading to obvious expansion at both cathode and anode. After applying AC for $15 \mathrm{~s}$, graphite foils transformed into loosely-packed layers with porous structure, resulting in exfoliated graphene sheets.

The exfoliated graphene flakes were subsequently transferred onto $\mathrm{Si} / \mathrm{SiO}_{2}$ substrates by the Langmuir-Blodgett method from dispersion. Figure $2 \mathbf{a}$ shows the scanning electron microscope (SEM) images of EG flakes. The nanosheets, with a broad size distribution, covered uniformly the $\mathrm{Si} / \mathrm{SiO}_{2}$ wafer. Based on the analysis of 100 flakes, over $70 \%$ of the lateral dimensions are between 1 and $5 \mu \mathrm{m}$ (Fig. 2b) and over $10 \%$ of flakes are larger than $5 \mu \mathrm{m}$. Statistical analysis on 464 flakes reveals an average flake area of $5.1 \mu \mathrm{m}^{2}$ (Fig. S7). Topographical tapping-mode atomic force microscopy (AFM) images provide evidence of thin flakes (Fig. 2c). The topographical profile revealed that the thickness of an EG flake amounts to $0.72 \mathrm{~nm}$, which is consistent with the thickness of single-layer graphene on silicon wafer. ${ }^{[23]}$ Interestingly, the height at flake edge was found being $0.95 \mathrm{~nm}$, i.e. is higher than that of the flake basal plane, possibly due to the presence of oxygen moieties. A thickness histogram of 20 randomly selected flakes demonstrates that $75 \%$ of the flakes range from monolayer to trilayers, providing an unambiguous evidence for the highly efficient nature of our exfoliation process (Fig. 2d). Selected area electron diffraction (SAED) from transmission electron microscopy (TEM) image (Fig. 2e) exhibits a typical hexagonal symmetric pattern. The diffraction at (210) plane is stronger than that at (110) plane, suggesting a bilayer graphene flake with high crystallinity. ${ }^{[24]}$ The Raman spectrum (Fig. 2f, excited by a $532 \mathrm{~nm}$ laser) was collected from the central part of an EG flake. It exhibits three dominate bands, including $D$ band at $1350 \mathrm{~cm}^{-1}, \mathrm{G}$ band at $1580 \mathrm{~cm}^{-1}$ and a symmetric 2D band at 2700 $\mathrm{cm}^{-1}$, in which the $\mathrm{D}$ band was caused by defects (boundaries or functional groups). The low value of $I_{d} / l_{g}$ ratio $(0.16)$ reveals a low level of disorders or defects at in-plane region of EG sheets. This value is much smaller than that of graphene materials based on GO (generally exceeding 1$)^{[25]}$ and anodic exfoliated graphene from aqueous electrolytes $(0.25-0.95){ }^{[12-13]}$

X-ray photoelectron spectroscopy (XPS) and Elemental analysis (EA) were performed to reveal the chemical composition of EG (Fig. 3a-3c, Table S1). Based on results from XPS, the oxygen content of the EG powder was evaluated to be 4.5 atom \%, thus being higher 
a
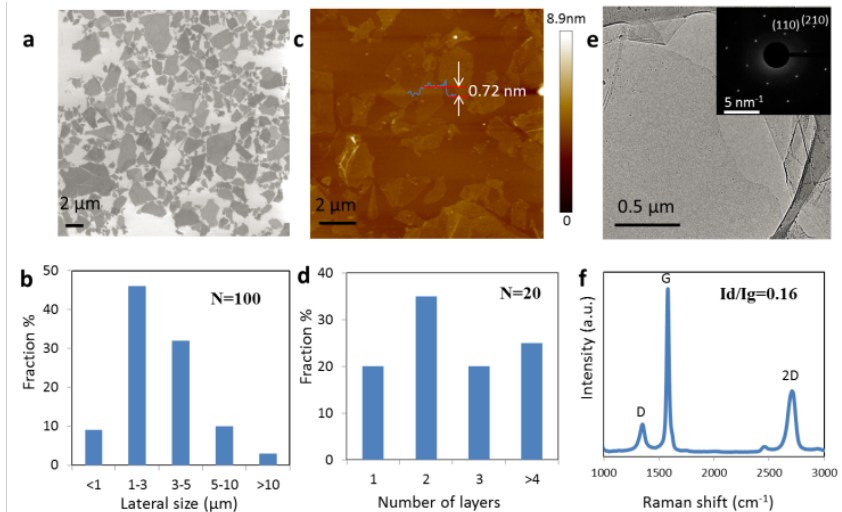

Figure 2. a) SEM image of $E G$ sheets on $\mathrm{Si} / \mathrm{SiO}_{2}$ wafer; b) statistical calculation of flake sizes from SEM image; c,d) AFM image of EG flakes and the corresponding height profile distribution; e) TEM image of a EG flake and its SAED pattern; f) Raman spectrum of EG (excited by $532 \mathrm{~nm}$ laser).

than that of the graphite precursor (1.8 atom \% oxygen). The overall oxygen is mainly distributed at the edges and grain boundaries of EG flakes, in the form of oxide groups. ${ }^{\text {[13a] }}$ The atomic ratio of carbon and oxygen $(\mathrm{C} / \mathrm{O})$ was calculated to be 21.2 , which is higher than our previous reports, ${ }^{[12 b, 13 a]}$ The high resolution of $C$ 1s peak is fitted into three peaks at $284.6 \mathrm{eV}, 285.3 \mathrm{eV}$ and $287.1 \mathrm{eV}$, corresponding to the $\mathrm{C}=\mathrm{C}, \mathrm{C}-\mathrm{OH}, \mathrm{C}=\mathrm{O}$ bonds, respectively. ${ }^{[26]}$ The peak related to the $\pi-\pi^{*}$ transition (shake-up) $(290.9 \mathrm{eV})$ is well visible after exfoliation, indicating that the conjugated aromatic structure is preserved. ${ }^{[27]}$ Epoxy groups (C-O-C) and carboxyl groups (-C(O)-O) are absent, most possibly due to the electrochemical reduction in the exfoliation process ${ }^{[28]}$ (the conversion reactions are proposed in Fig. S8). As an important benefit, the periodically switched potential indeed helps to protect EG against excessive oxidation by introducing destructive epoxy groups.
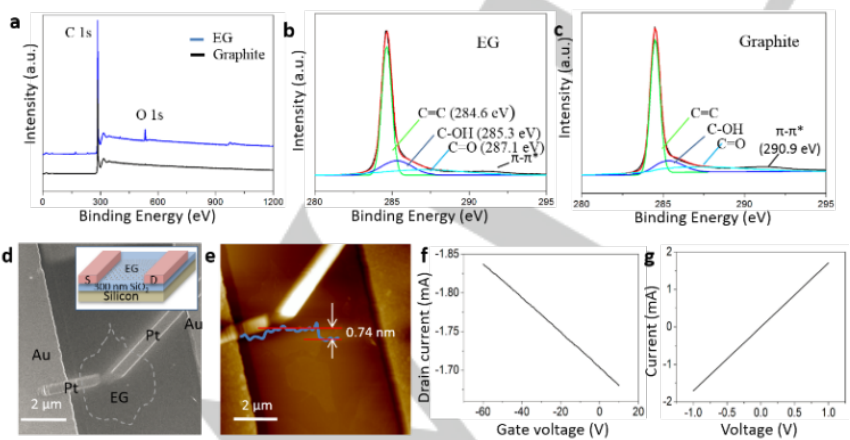

Figure 3. a) XPS survey of EG powder and graphite foil; High resolution $\mathrm{C} 1 \mathrm{~s}$ spectrum of (b) EG and (c) graphite, respectively; d,e) SEM (insert: geometry) and AFM of fabricated FET device; f) Transfer curve and g) current-voltage (I-V) curve of a monolayer EG flake.
Field-effect transistor (FET) devices were fabricated to reveal the electronic property of EG. Figure 3d reports the SEM image of asprepared FET device on the $\mathrm{Si} / \mathrm{SiO}_{2}$ wafer. The isolated $\mathrm{EG}$ flake in the channel is connected by a lithographed Pt wire to gold source/drain electrodes. AFM and thickness analysis (Fig. 3e) confirm the presence of a monolayer flake. According to the transfer curve (Fig. 3f) and I-V curve (Fig. 3g), the individual EG sheet possesses a remarkably high hole mobility of $430 \mathrm{~cm}^{2} \cdot \mathrm{V}^{-1} \cdot \mathrm{s}^{-1}$ and a low sheet resistance of $1.98 \mathrm{k}^{2} \mathrm{sq}^{-1}$. In addition, EG flakes with various thickness have been examined (Table S2). Thanks to fast exfoliation as well as electrochemical reduction, the average hole mobility based on a single EG flake in this work is obviously higher than that of chemically reduced $\mathrm{GO}\left(0.001-123 \mathrm{~cm}^{2} \cdot \mathrm{V}^{-1} \cdot \mathrm{s}^{-1}\right)^{[29]}$ and electrochemically exfoliated graphene by direct current (233-405 $\left.\mathrm{cm}^{2} \cdot \mathrm{V}^{-1} \cdot \mathrm{s}^{-1}\right)^{[12 \mathrm{~b}, 13]}$ (Table S3). Moreover, profiting from the excellent solution-processability of EG, a graphene thin film on glass substrate was prepared by simple filtration-transfer method. Graphene film with $10 \mathrm{~nm}$ thickness provides a low mean sheet resistance of 1.56 $\mathrm{k} \Omega \mathrm{sq}^{-1}$ (with conductivity of $640 \mathrm{~S} \mathrm{~cm}^{-1}$ ). After doping by nitric acid $(65 \%)$ at ambient condition, the value further drops down to $0.92 \mathrm{k} \Omega$ $\mathrm{sq}^{-1}$ (with conductivity of $1087 \mathrm{~S} \mathrm{~cm}^{-1}$ ).

To illustrate the potential use of the developed EG in battery applications, we simply mixed an EG dispersion with commercially available cathode material (lithium iron phosphate, $\mathrm{LiFePO}_{4}$ ) in DMF under a sonication bath. The surface of $\mathrm{LiFePO}_{4}$ particles was homogeneously coated with a thin layer of EG (Fig. S9). After filtration, EG-wrapped $\mathrm{LiFePO}_{4}$ particles (EG-LFP) with low mass loading of EG (2.0 wt \%) were used as cathode in half-cells, in which a lithium foil was assembled as the anode. The voltage profile of EGLFP with $1 \mathrm{C}\left(1 \mathrm{C}=170 \mathrm{~mA} \mathrm{~g}^{-1}\right)$ (Fig. 4a) revealed a capacity of 157 $\mathrm{mAh} \mathrm{g}^{-1}$ at the $20^{\text {th }}$ cycle. After the activation of active material $\left(\mathrm{LiFePO}_{4}=\mathrm{FePO}_{4}+\mathrm{Li}^{+}+e^{-}\right),{ }^{\left[{ }^{30]}\right.}$ the capacity was further increased to $167 \mathrm{mAh} \mathrm{g}^{-1}$ at $200^{\text {th }}$ cycle, which was stable till the $500^{\text {th }}$ cycle. Fig. 4b shows the discharge rate capability at different charging/discharging rates ranging from $1 \mathrm{C}$ to $5 \mathrm{C}$. The capacity faded at a high discharging current, however, $~ 50 \%$ of capacity was still retained at $5 \mathrm{C}$. Once the discharging rate reverted to $1 \mathrm{C}$, the capacity of EG-LFP was reached again at $\sim 165 \mathrm{mAh} \mathrm{g}^{-1}$. In particular, EG-LFP demonstrated excellent cycling stability at $1 \mathrm{C}$ rate (Fig. 4c). The average Coulombic efficiency was calculated to be $99.3 \%$. A high discharging capacity of $167 \mathrm{mAh} \mathrm{g}^{-1}$ was obtained after 500 cycles. This value is approaching the theoretical capacity of $\mathrm{LiFePO}_{4}\left(170 \mathrm{mAh} \mathrm{g}{ }^{-1}\right)$. The superior performance of EG-LFP results from high-quality graphene, which significantly improves the electron transfer during the cycling process, even though a very low weight percentage of graphene (2.0 wt \%) has been used. 

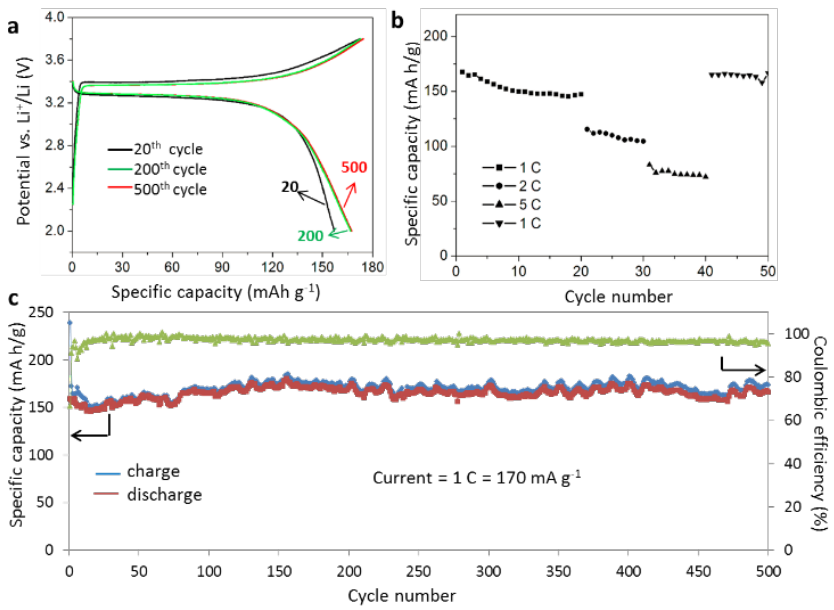

Figure 4. a) The voltage profile for the $20^{\text {th }}, 200^{\text {th }}$ and $500^{\text {th }}$ cycle of charging and discharging (at a current rate of $1 \mathrm{C}$ ) of EG-LiFePO 4 hybrid; b) the discharge rate capability at various charge/discharge rates; c) cycling performance of $\mathrm{EG}-\mathrm{LiFePO}{ }_{4}$ hybrid upon prolonged 500 cycles and its Coulombic efficiency at $1 \mathrm{C}$.

In summary, we have developed a facile, simple and fast strategy to exfoliate graphite by alternating current to achieve high exfoliation efficiency ( $80 \%$ total yield, $75 \%$ of the graphene are 1-3 layers) and ultrahigh production capacity (over 20 gram per hour in a lab test). The exfoliated graphene owns large flakes, low degree of defects and a remarkable hole mobility up to $430 \mathrm{~cm}^{2} \cdot \mathrm{V}^{-1} \cdot \mathrm{s}^{-1}$. This straightforward method provides EG dispersion with excellent processability, which is favorable for the fabrication of conducting films and integrated hybrids. The high-quality solution-processable EG also holds great promise for a wide spectrum of applications, such as inkjet printing, solar cells, catalysis and composites.

\section{Acknowledgements}

The authors gratefully acknowledge financial support by ERC Grant on 2DMATER and UPGreen, EC under Graphene Flagship (No. CNECT-ICT-604391). The Marie Sklodowska-Curie ETN projects SYNCHRONICS (GA 643238), the Agence Nationale de la Recherche through the LabEx project Chemistry of Complex Systems (ANR-10-LABX-0026_CSC), and the International Center for Frontier Research in Chemistry (icFRC). The authors thank Dr. Alexey A. Popov and Dr. Stanislav Avdoshenko (Lebniz Institute for Solid State and Materials Research) for insightful discussions; Dr. Wulf Grählert (Fraunhofer-Institut für Werkstoff- und Strahltechnik) for FT-IR gas analysis. Sheng Yang would like to acknowledge financial support from China Scholarship Council (CSC).

Keywords: graphite exfoliation • graphene • electrochemistry • field-effect transistor $\cdot$ cathode material
[2]

[1] a) K. S. Novoselov, A. K. Geim, S. V. Morozov, D. Jiang, Y. Zhang, S. V. Dubonos, I. V. Grigorieva, A. A. Firsov, Science 2004, 306, 666-669; b) V. Leon, M. Quintana, M. A. Herrero, J. L. G. Fierro, A. d. I. Hoz, M. Prato, E. Vazquez, Chem. Commun. 2011, 47, 10936-10938.

a) Z. Y. Xia, S. Pezzini, E. Treossi, G. Giambastiani, F. Corticelli, V. Morandi, A. Zanelli, V. Bellani, V. Palermo, Adv. Funct. Mater. 2013, 23, 4684-4693; b) A. Ciesielski, P. Samori, Chem. Soc. Rev. 2014, 43, 381-398.

D. Voiry, J. Yang, J. Kupferberg, R. Fullon, C. Lee, H. Y. Jeong, H. S. Shin, M. Chhowalla, Science 2016, 353, 1413-1416.

A. M. Dimiev, G. Ceriotti, A. Metzger, N. D. Kim, J. M. Tour, ACS Nano 2016, 10, 274-279.

[5] C. Gómez-Navarro, R. T. Weitz, A. M. Bittner, M. Scolari, A. Mews, M. Burghard, K. Kern, Nano Lett. 2007, 7, 34993503.

[6] a) F. Bonaccorso, A. Bartolotta, J. N. Coleman, C. Backes, Adv. Mater. 2016, 28, 6136-6166; b) A. Ciesielski, S. Haar, M. El Gemayel, H. Yang, J. Clough, G. Melinte, M. Gobbi, E. Orgiu, M. V. Nardi, G. Ligorio, V. Palermo, N. Koch, O. Ersen, C. Casiraghi, P. Samorì, Angew. Chem. Int. Ed. 2014, 53, 10355-10361.

[7] J. N. Coleman, Acc. Chem. Res. 2013, 46, 14-22.

[8] K. R. Paton, E. Varrla, C. Backes, R. J. Smith, U. Khan, A. O'Neill, C. Boland, M. Lotya, O. M. Istrate, P. King, T. Higgins, S. Barwich, P. May, P. Puczkarski, I. Ahmed, M. Moebius, H. Pettersson, E. Long, J. Coelho, S. E. O'Brien, E. K. McGuire, B. M. Sanchez, G. S. Duesberg, N. McEvoy, T. J. Pennycook, C. Downing, A. Crossley, V. Nicolosi, J. N. Coleman, Nat. Mater. 2014, 13, 624-630.

[9] C. T. J. Low, F. C. Walsh, M. H. Chakrabarti, M. A. Hashim, M. A. Hussain, Carbon 2013, 54, 1-21.

[10] S. Yang, M. R. Lohe, K. Müllen, X. Feng, Adv. Mater. 2016, 28, 6213-6221.

[11] X. Wang, P. F. Fulvio, G. A. Baker, G. M. Veith, R. R. Unocic, S. M. Mahurin, M. Chi, S. Dai, Chem. Commun. 2010, 46, 4487-4489.

[12] a) K. S. Rao, J. Sentilnathan, H.-W. Cho, J.-J. Wu, M. Yoshimura, Adv. Funct. Mater. 2015, 25, 298-305; b) K. Parvez, R. Li, S. R. Puniredd, Y. Hernandez, F. Hinkel, S. Wang, X. Feng, K. Müllen, ACS Nano 2013, 7, 3598-3606.

[13] a) K. Parvez, Z.-S. Wu, R. Li, X. Liu, R. Graf, X. Feng, K. Müllen, J. Am. Chem. Soc. 2014, 136, 6083-6091; b) S. Yang, S. Brüller, Z.-S. Wu, Z. Liu, K. Parvez, R. Dong, F. Richard, P. Samorì, X. Feng, K. Müllen, J. Am. Chem. Soc. 2015, 137, 13927-13932. 
Z. Zeng, Z. Yin, X. Huang, H. Li, Q. He, G. Lu, F. Boey, H. Zhang, Angew. Chem. Int. Ed. 2011, 50, 11093-11097.

[15] A. J. Cooper, N. R. Wilson, I. A. Kinloch, R. A. W. Dryfe, Carbon 2014, 66, 340-350.

[16] A. M. Abdelkader, I. A. Kinloch, R. A. W. Dryfe, ACS Appl. Mater. Interfaces 2014, 6, 1632-1639. W. Sirisaksoontorn, A. A. Adenuga, V. T. Remcho, M. M. Lerner, J. Am. Chem. Soc. 2011, 133, 12436-12438.

[18] X. Feng, X. Wang, W. Cai, S. Qiu, Y. Hu, K. M. Liew, ACS Appl. Mater. Interfaces 2016, 8, 25552-25562.

[19] M. K. Punith Kumar, M. Nidhi, C. Srivastava, RSC Adv. 2015, 5, 24846-24852.

[20] L. A. Girifalco, M. Hodak, Phys. Rev. B 2002, 65, 125404.

[21] X. Wang, I. Kholmanov, H. Chou, R. S. Ruoff, ACS Nano 2015, 9, 8737-8743.

a) C.-Y. Yang, C.-L. Wu, Y.-H. Lin, L.-H. Tsai, Y.-C. Chi, J.-H. Chang, C.-I. Wu, H.-K. Tsai, D.-P. Tsai, G.-R. Lin, Opt. Mater. Express 2013, 3, 1893-1905; b) Z. Y. Xia, G. Giambastiani, C. Christodoulou, M. V. Nardi, N. Koch, E. Treossi, V. Bellani, S. Pezzini, F. Corticelli, V. Morandi, A. Zanelli, V. Palermo, ChemPlusChem, 2014, 79, 439-446.
[23] Z. Cheng, Q. Zhou, C. Wang, Q. Li, C. Wang, Y. Fang, Nano Lett. 2011, 11, 767-771. Z. Sun, Z. Yan, J. Yao, E. Beitler, Y. Zhu, J. M. Tour, Nature 2010, 468, 549-552.

I. K. Moon, J. Lee, R. S. Ruoff, H. Lee, Nat. Commun. 2010, 1, 73

[26] M. Matsumoto, Y. Saito, C. Park, T. Fukushima, T. Aida, Nat. Chem. 2015, 7, 730-736.

[27] A. Ganguly, S. Sharma, P. Papakonstantinou, J. Hamilton, J. Phys. Chem. C 2011, 115, 17009-17019.

[28] K. Hu, X. Xie, T. Szkopek, M. Cerruti, Chem. Mater. 2016, 28, 1756-1768.

a) G. Eda, G. Fanchini, M. Chhowalla, Nat. Nanotech. 2008, 3, 270-274; b) H. Feng, R. Cheng, X. Zhao, X. Duan, J. Li, Nat. Commun. 2013, 4, 1539.

[30] B. Lung-Hao Hu, F.-Y. Wu, C.-T. Lin, A. N. Khlobystov, L.J. Li, Nat. Commun. 2013, 4, 1687. 